\title{
Something Old, Something New: Biomarkers in Rheumatoid Arthritis
}
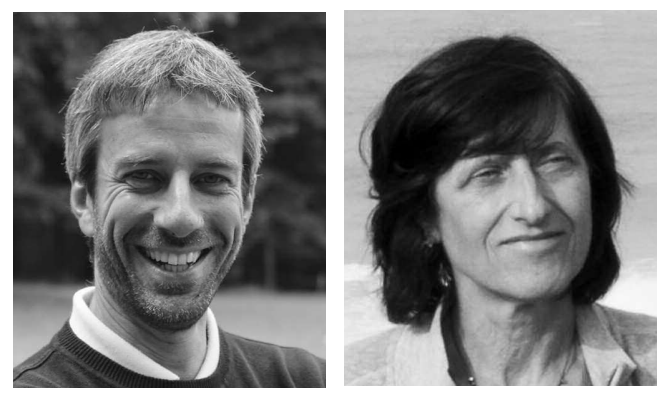

In this issue of The Journal, Maksymowych, et al ${ }^{1}$ propose

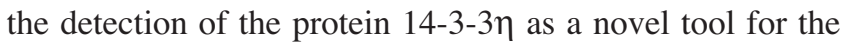
diagnosis of rheumatoid arthritis (RA).

The protein $14-3-3 \eta$ belongs to a family of phosphoserine/phosphothreonine-recognition proteins that regulate the activity of several different ligands in various signaling pathways. The expression of these proteins is controlled at the genomic level and post-translationally; a large body of evidence supports the hypothesis that their abnormal expression and/or interaction with targets contributes to a large number of human diseases ${ }^{2}$. The isoform $\eta$ is among the most highly induced of these proteins in activated B cells where, by interacting with activation-induced cytidine deaminase, it regulates class-switch recombination ${ }^{3}$. It is the only isoform that is detectable in increased amounts in microparticles from systemic lupus erythematosus sera ${ }^{4}$ and in synovial fluids from patients with $\mathrm{RA}^{5}$.

Maksymowych, et $a l^{1}$ studied the serum levels of 14-3-3 $\eta$ in 2 cohorts of patients with RA, one with early RA and one with established RA, who were being treated with disease-modifying antirheumatic drugs (DMARD) but not biologicals. Normal healthy subjects and patients affected by osteoarthritis, chronic arthritis [psoriatic arthritis (PsA), spondyloarthritis, gout], connective tissue disorders, and other inflammatory conditions served as controls. The levels of 14-3-3n could discriminate patients with RA from healthy controls and disease controls with high sensitivity and specificity (77\% and $92.5 \%$ in established RA, $64 \%$ and $92.6 \%$ in early RA). Moreover, the levels of $14-3-3 \eta$ were higher in RA patients with higher C-reactive protein and 28-joint Disease Activity Score levels ${ }^{1}$ and in those showing radiographic progression ${ }^{6}$. These data, together with the observed downregulation by anti-tumor necrosis factor treatment, suggest that protein levels reflect ongoing articular damage.

It is of interest to note that not all RA patients with high levels of $14-3-3 \eta$ are positive for anticitrullinated protein antibodies (ACPA) or for rheumatoid factor (RF); thus detection of $14-3-3 \eta$ would complement existing assays and allow the diagnosis of RA in a higher percentage of cases. These data suggest that the introduction of new, complementary assays could enhance the accuracy of diagnostic procedures and improve our ability to predict disease progression in RA.

\section{EARLY DIAGNOSIS OF RA}

The detection of RA in its early stages is often challenging, and the measurement of ACPA levels is crucial. Given the specificity of ACPA for RA, a positive result in any assay has a high predictive value for diagnosis; $40 \%$ positivity has been reported using the cyclic citrullinated peptide (CCP) assay and similar or slightly lower percentages by other assays. Unfortunately, with all the assays now available, the frequency of a positive result is lower in early RA - when treatment would be most efficacious - than in later disease. A small increment in the frequency of positive results may be obtained by conducting parallel assays using different citrullinated substrates. In fact, the overlap of the CCP assay with the other tests for ACPA is not complete: sera that are anti-CCP-negative, but positive for antiviral citrullinated peptide, anticitrullinated fibrinogen, or anti-modified citrullinated vimentin antibodies do exist, and have been reported in $2 \%-7 \%$ of tested RA populations ${ }^{7,8}$.

Therefore, even when assayed using different citrullinated antigens, a proportion of RA sera - roughly $20 \%$ in established disease, but around $50 \%$ in early disease - are ACPA-negative. The latter patient population could benefit from testing with a new biomarker such as the protein 14-3-3ך.

When attempting to diagnose a disease in its initial stages, the specificity of the biomarker is critical. While there are an impressive amount of data on ACPA, only a small number of studies on the $14-3-3 \eta$ protein have been

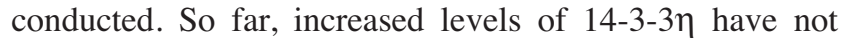
been detected in inflammatory disorders, even in those affecting the joints. Higher levels (although lower than in

See Novel diagnostic marker for RA, page 2104

Personal non-commercial use only. The Journal of Rheumatology Copyright (c) 2014. All rights reserved. 
RA) have been reported in erosive PsA, raising the possibility that the protein's specificity may be more for the particular condition of erosive arthritis than for RA in general. The analysis of a wider cohort of patients affected by erosive arthritis, different from RA, could answer this question.

A second very pertinent issue in early diagnosis is the presence of ACPA in healthy subjects. In fact, ACPA may precede the onset of the disease by decades but can also be detected in the healthy relatives of patients with RA. Here the CCP test may be informative when the antibody level is taken into account. In fact, higher titers of anti-CCP usually correspond to the presence of a wider variety of antibodies, which is suggestive of a pre-RA state. In these patients, ACPA profiling is deemed to be extremely helpful in gauging the risk of developing the disease. In fact, the analysis of pre-RA sera has shown that the immune response to citrullinated epitopes is initially restricted but expands with time, indicating epitope spreading long before the onset of the disease ${ }^{9}$. Similarly, subjects affected by undifferentiated arthritis that then evolves toward RA are characterized by the recognition of a higher number of citrullinated peptides ${ }^{10,11}$. This expansion in the fine specificity of ACPA is correlated with the appearance of preclinical inflammation. Together with ACPA profiling, the identification of a new biomarker may contribute to the better prognostic evaluation of patients with undifferentiated arthritis.

\section{PROGNOSIS OF RA}

Early therapeutic intervention in patients at risk of developing persisting and aggressive disease is critical in RA. The tools available to predict the severity of the disease are clinical evaluation, imaging techniques, and the assaying of autoantibodies and other serological biomarkers.

In terms of serology, RF and ACPA are useful variables for determining the prognosis. The presence of RF at baseline has significant predictive value for the development of erosions; RF seropositivity also predicts persistent synovitis and the necessity for intensive treatment. However, there is disagreement regarding the value of RF as a predictor of remission and loss of function.

It has been shown that ACPA positivity at baseline has a predictive value for subsequent structural damage, in close association with the persistence of synovitis and the decline of function during the course of the disease. Most ACPA-positive patients with RA already have joint erosions at diagnosis and ACPA positivity in early RA is related to radiographic progression, even in patients initially treated with a combination of DMARD ${ }^{12}$. Moreover, it has been reported that ACPA-negative and ACPA-positive patients differ in their requirements for combination therapy ${ }^{13}$.

On the other hand, RF and ACPA are not associated with any of the extraarticular manifestations of the disease. In this respect, although the analysis of the fine specificity of
ACPA provides no additional information in terms of disease activity or calculating the progression score ${ }^{14}$, it might contribute to the prediction of extraarticular involvement ${ }^{15}$.

It is unclear whether joint destruction and the persistence of RA are due to the same mechanisms. Factors clearly associated with both are ACPA and RF positivity, HLA shared epitope (SE) status, and the duration of symptoms. Inflammatory markers are associated with the severity of joint damage but not with the persistence of the disease. Nonetheless, taken together these variables account for $32 \%$ of the total variance in predicting joint destruction and disease progression, leaving $68 \%$ of the variance unaccounted for ${ }^{16}$.

Finally, patients with RA who test negative for RF, ACPA, and HLA-SE but suffer from erosive disease do exist, and the absence of serological markers may limit early appropriate treatment for these patients ${ }^{17}$.

Better predictors of disease outcome are needed and these include soluble biomarkers that can be detected early in the course of the disease.

\section{PERSPECTIVES}

Any biomarker that can contribute to an early diagnosis and that allows a clearer stratification of the disease's persistence and severity is of utmost interest for patients with RA. Provided that future studies confirm what has so far been observed, the protein 14-3-3 $\eta$ could provide a useful addition to our diagnostic resources. It is correlated to joint damage and is not connected with the immune response, and therefore would in principle be complementary to ACPA and RF detection. In fact, the protein 14-3-3 $\eta$ is not a marker of ACPA-negative RA nor does it define a subset of ACPA-negative or RF-negative patients.

More data must be collected on the cellular source of the protein and on the mechanisms leading to its release to establish whether it can be considered the marker of a disease-specific inflammatory pathway.

The analysis of wider cohorts of patients with RA that are well characterized from the clinical, serological, and genetic points of view will allow us to integrate this new biomarker into the diagnostic and followup procedures for patients with RA. Future longitudinal studies will show whether inclusion of protein 14-3-3 $\eta$ in models for predicting progression of joint damage could enhance the sensitivity of procedures for discriminating between patients at high or low risk.

In this light, alongside its consolidated role in the diagnosis of RA, we may learn that ACPA could provide further information. By focusing on the detection of potentially pathogenic subtypes of ACPA (such as those that fix complement $^{18}$, or those lacking syalic acid $^{19}$ ), a correlation of antibodies with disease severity or disease subtypes may emerge.

In the future, the diagnosis of RA could benefit greatly

Personal non-commercial use only. The Journal of Rheumatology Copyright @ 2014 . All rights reserved 
from the gathering of information through the assaying of many variables simultaneously - for example, a cluster of biomarkers associated with genotyping - leading to the more accurate prediction of disease outcome and to more effective, individualized treatment.

\section{FEDERICO PRATESI, PhD; PAOLA MIGLIORINI, MD,}

Clinical Immunology and Allergy Unit, Department of Clinical and Experimental Medicine, University of Pisa,

Pisa, Italy.

Address correspondence to Dr. P. Migliorini, Clinical Immunology and Allergy Unit, Department of Clinical and Experimental Medicine, University of Pisa, Via Roma 67, 56126 Pisa, Italy. E-mail: paola.migliorini@med.unipi.it

\section{REFERENCES}

1. Maksymowych W, Naides S, Bykerk V, Siminovitch K, van Schaardenburg D, Boers M, et al. Serum 14-3-3 $\eta$ is a novel marker that complements current serological measurements to enhance detection of patients with rheumatoid arthritis. J Rheumatol 2014;41:2104-13.

2. Zhao J, Meyerkord CL, Du Y, Khuri FR, Fu H. 14-3-3 proteins as potential therapeutic targets. Semin Cell Dev Biol 2011;22:705-12.

3. Lam T, Thomas LM, White CA, Li G, Pone EJ, Xu Z, et al. Scaffold functions of 14-3-3 adaptors in B cell immunoglobulin class switch DNA recombination. PLoS One 2013;8:e80414.

4. Østergaard O, Nielsen CT, Iversen LV, Tanassi JT, Knudsen S, Jacobsen $\mathrm{S}$, et al. Unique protein signature of circulating microparticles in systemic lupus erythematosus. Arthritis Rheum 2013;65:2680-90.

5. Kilani RT, Maksymowych WP, Aitken A, Boire G, St-Pierre Y, Li Y, et al. Detection of high levels of 2 specific isoforms of 14-3-3 proteins in synovial fluid from patients with joint inflammation. J Rheumatol 2007;34:1650-7.

6. Maksymowych WP, van der Heijde D, Allaart CF, Landewé R, Boire G, Tak P, et al. 14-3-3eta is a novel mediator associated with the pathogenesis of rheumatoid arthritis and joint damage. Arthritis Res Ther 2014;16:R99.

7. Nicaise-Roland P, Nogueira L, Demattei C, de Chaisemartin L, Rincheval N, Cornillet M, et al. Autoantibodies to citrullinated fibrinogen compared with anti-MCV and anti-CCP2 antibodies in diagnosing rheumatoid arthritis at an early stage: data from the French ESPOIR cohort. Ann Rheum Dis 2013;72:357-62.

8. Pratesi F, Tommasi C, Anzilotti C, Puxeddu I, Sardano E, Di Colo $\mathrm{G}$, et al. Antibodies to a new viral citrullinated peptide, VCP2: fine specificity and correlation with anti-cyclic citrullinated peptide (CCP) and anti-VCP1 antibodies. Clin Exp Immunol 2011; 164:337-45.
9. Brink M, Hansson M, Mathsson L, Jakobsson PJ, Holmdahl R, Hallmans G, et al. Multiplex analyses of antibodies against citrullinated peptides in individuals prior to development of rheumatoid arthritis. Arthritis Rheum 2013;65:899-910.

10. van de Stadt LA, de Koning MH, van de Stadt RJ, Wolbink G, Dijkmans BA, Hamann D, et al. Development of the anti-citrullinated protein antibody repertoire prior to the onset of rheumatoid arthritis. Arthritis Rheum 2011;63:3226-33.

11. van der Woude D, Rantapää-Dahlqvist S, Ioan-Facsinay A, Onnekink C, Schwarte CM, Verpoort KN, et al. Epitope spreading of the anti-citrullinated protein antibody response occurs before disease onset and is associated with the disease course of early arthritis. Ann Rheum Dis 2010;69:1554-61.

12. Mustila A, Korpela M, Haapala AM, Kautiainen H, Laasonen L, Möttönen T, et al. Anti-citrullinated peptide antibodies and the progression of radiographic joint erosions in patients with early rheumatoid arthritis treated with FIN-RACo combination and single disease-modifying antirheumatic drug strategies. Clin Exp Rheumatol 2011;29:500-5

13. Seegobin SD, Ma MH, Dahanayake C, Cope AP, Scott DL, Lewis $\mathrm{CM}$, et al. ACPA-positive and ACPA-negative rheumatoid arthritis differ in their requirements for combination DMARDs and corticosteroids: secondary analysis of a randomized controlled trial. Arthritis Res Ther 2014;16:R13.

14. van Beers JJ, Willemze A, Jansen JJ, Engbers GH, Salden M, Raats $\mathrm{J}$, et al. ACPA fine-specificity profiles in early rheumatoid arthritis patients do not correlate with clinical features at baseline or with disease progression. Arthritis Res Ther 2013;15:R140.

15. Giles JT, Danoff SK, Sokolove J, Wagner CA, Winchester R, Pappas $\mathrm{DA}$, et al. Association of fine specificity and repertoire expansion of anticitrullinated peptide antibodies with rheumatoid arthritis associated interstitial lung disease. Ann Rheum Dis 2014;73:1487-94.

16. de Rooy DP, van der Linden MP, Knevel R, Huizinga TW, van der Helm-van Mil AH. Predicting arthritis outcomes - what can be learned from the Leiden Early Arthritis Clinic? Rheumatology 2011;50:93-100.

17. Ohmura K, Terao C, Maruya E, Katayama M, Matoba K, Shimada $\mathrm{K}$, et al. Anti-citrullinated peptide antibody-negative RA is a genetically distinct subset: a definitive study using only bone-erosive ACPA-negative rheumatoid arthritis. Rheumatology 2010;49:2298-304.

18. Trouw LA, Haisma EM, Levarht EW, van der Woude D, Ioan-Facsinay A, Daha MR, et al. Anti-cyclic citrullinated peptide antibodies from rheumatoid arthritis patients activate complement via both the classical and alternative pathways. Arthritis Rheum 2009;60:1923-31.

19. Scherer HU, van der Woude D, Ioan-Facsinay A, el Bannoudi H, Trouw LA, Wang J, et al. Glycan profiling of anti-citrullinated protein antibodies isolated from human serum and synovial fluid. Arthritis Rheum 2010;62:1620-9.

J Rheumatol 2014;41:2091-3; doi:10.3899/jrheum.141069 